CLINICAL STUDY

\title{
Gestational diabetes mellitus among Norwegian women with polycystic ovary syndrome: prevalence and risk factors according to the WHO and the modified IADPSG criteria
}

\author{
R Helseth, E Vanky ${ }^{1,3}$, Ø Salvesen ${ }^{4}$ and S M Carlsen ${ }^{2,4}$ \\ Department of Medicine, Drammen Hospital, Vestre Viken, Norway, Departments of ${ }^{1}$ Obstetrics and Gynecology and ${ }^{2}$ Endocrinology, St Olavs Hospital, \\ Trondheim University Hospital, Trondheim, Norway, ${ }^{3}$ Department of Women's and Children's Health and ${ }^{4}$ Unit for Applied Clinical Research, Department \\ of Cancer Research and Molecular Medicine, Norwegian University of Science and Technology, PO Box 8905, 7491 Trondheim, Norway \\ (Correspondence should be addressed to S M Carlsen at Unit for Applied Clinical Research, Department of Cancer Research and Molecular Medicine, \\ Norwegian University of Science and Technology; Email: sven.carlsen@ntnu.no)
}

\begin{abstract}
Objective: The consequences of the recently proposed International Association of Diabetes in Pregnancy Study Group (IADPSG) criteria for gestational diabetes mellitus (GDM) in women with polycystic ovary syndrome (PCOS) are not known. We compared the prevalence rates and risk factors for GDM in PCOS women according to both the WHO and the modified IADPSG criteria.

Design: Post hoc analyses from a randomized, multicenter study were used.

Methods: Fasting and 2-h plasma glucose levels were measured using a $75 \mathrm{~g}$ oral glucose tolerance test. GDM was diagnosed according to both the WHO and the modified IADPSG criteria.

Results: The prevalence rates of GDM according to the WHO and the modified IADPSG criteria were 9.2 and $15.0 \%$ at week $12,18.7$ and $18.7 \%$ at week 19 , and 25.6 and $24.2 \%$ at week 32 . Shorter stature and increased insulin levels were correlated with WHO-GDM, but not with modified IADPSG-GDM at weeks 12 and 19. Less weight gain in pregnancy predicted GDM according to both sets of criteria. GDM diagnosis was correlated with less maternal weight loss the first year post-partum.

Conclusions: No difference was found in the prevalence of GDM between the two sets of criteria used. Less weight gain in pregnancy was associated with GDM, independent of the diagnostic criteria used. Reduced weight loss the first year post-partum in women with GDM raises the question of whether GDM diagnosis per se or the fact that these women lose less weight after pregnancy predicts later diabetes mellitus.
\end{abstract}

European Journal of Endocrinology 169 65-72

\section{Introduction}

The incidence of diabetes mellitus is increasing worldwide. This is also the case for diabetes in pregnancy - gestational diabetes mellitus (GDM) (1, 2). The association between GDM and adverse pregnancy outcomes is well documented $(3,4,5,6)$. The linear association between increasing maternal blood glucose levels and adverse pregnancy outcomes has raised the question of which criteria should be used for GDM diagnosis (7). In some countries, the WHO criteria have been substituted by the stricter International Association for Diabetes in Pregnancy Study Group (IADPSG) criteria (8). The IADPSG criteria increases the prevalence of GDM (9).

Polycystic ovary syndrome (PCOS) is the commonest endocrine disorder among women of fertile age, affecting $\sim 10-15 \%$ of the fertile female population based on the Rotterdam criteria. The NIH criteria give a somewhat lower PCOS prevalence rate of $6.5 \%$ (10).
A PCOS prevalence rate of $14.2 \%$ according to the Rotterdam criteria has recently been reported from Norway (11). PCOS is characterized by hyperandrogenism, oligomenorrhea, and polycystic ovaries. According to the Rotterdam criteria, PCOS diagnosis requires the presence of at least two of the three criteria (12). Women with PCOS are at an increased risk of developing GDM $(13,14,15,16,17)$. Women with both PCOS and GDM have a higher risk of developing pregnancyinduced hypertension and preeclampsia and of delivering preterm than those with GDM only (18). Newborns of women with both PCOS and GDM have an increased risk of developing neonatal hyperbilirubinemia (18). Higher levels of oxidative stress markers have recently been reported in neonates of PCOS women, suggesting that PCOS offspring may be at an increased risk of developing later metabolic and cardiovascular diseases (19).

The prevalence of GDM in women with PCOS according to the IADPSG criteria is not known. Whether 
the WHO and the IADPSG criteria identify the same risk factors for GDM development has not been studied. Our aims were to explore the prevalence of GDM in women with PCOS according to both the WHO and the modified IADPSG criteria and to compare the risk factors for GDM development according to the two sets of criteria.

\section{Subjects and methods}

\section{Study design}

We used data from a previously reported prospective, randomized, double-blind, multicenter study, the PregMet (metformin treatment in pregnant PCOS women) study, where treatment with $2000 \mathrm{mg}$ metformin daily from the first trimester to delivery was compared with that with placebo (20). Inclusion criteria were as follows: i) PCOS diagnosed before pregnancy according to the Rotterdam criteria; ii) age $18-45$ years; iii) gestational age between 5 and 12 weeks; and iv) a singleton viable fetus shown on ultrasonography. Inclusion was independent of the mode of conception, including assisted reproductive techniques. Exclusion criteria were as follows: i) alanine aminotransferase concentration >90 IU/l; ii) serum creatinine concentration $>130 \mu \mathrm{mol} / \mathrm{l}$; iii) known alcohol abuse; iv) previously diagnosed diabetes mellitus or fasting serum glucose concentration $>7.0 \mathrm{mmol} / \mathrm{l}$ at the time point of inclusion, $v$ ) treatment with oral glucocorticoids; or vi) use of drugs known to interfere with metformin.

The participants were enrolled at 11 study centers (three university hospitals, seven local hospitals, and one gynecological specialist practice). Overt diabetes mellitus, kidney disease, or liver disease was ruled out before inclusion into the study by determining fasting plasma glucose, serum creatinine, and alanine aminotransferase concentrations. At inclusion, before randomization, a $75 \mathrm{~g}$ oral glucose tolerance test (OGTT) and drawing of fasting blood samples were performed. Two-hundred and seventy-four pregnant women were then randomly assigned to either metformin or placebo treatment. All the participants received written and verbal diet advice according to the general guidelines for all pregnant women in Norway. Women diagnosed with GDM according to the WHO criteria used in the original randomized control trial (RCT) received more thorough diet advice. The detailed description of the PregMet study has been published elsewhere $(20,21)$.

All study participants gave written informed consent before inclusion into the study. The Committee for Medical Research Ethics of Health Region IV, Norway (145-04), and The Norwegian Medicines Agency (2004-000792-33) approved the study. The Declaration of Helsinki was followed throughout the study, and the study was conducted according to the principles of Good Clinical Practice. The study is registered at www.clinicaltrials.gov as NCT00159536.

\section{GDM criteria}

GDM was diagnosed i) according to the WHO criteria as fasting plasma glucose concentration $\geq 7.0 \mathrm{mmol} / \mathrm{l}$ and/or 2-h plasma glucose concentration $\geq 7.8 \mathrm{mmol} / \mathrm{l}$ during a 75 g OGTT at inclusion, pregnancy week 19, and/or pregnancy week 32 and ii) according to the modified IADPSG criteria as fasting plasma glucose concentration $\geq 5.1 \mathrm{mmol} / \mathrm{l}$ and/or 2 -h plasma glucose concentration $\geq 8.5 \mathrm{mmol} / \mathrm{l}$ at the same time points.

One-hour plasma glucose levels, part of the IADPSG criteria, were not measured as we used data from a RCT designed, planned, and initiated before the establishment of the IADPSG criteria. In the HAPO study, $11.1 \%$ of the GDM diagnosis according to the IADPSG criteria was set by one elevated glucose value, while $5.0 \%$ was set by two or three elevated glucose values. Provided that the elevation of glucose values is evenly distributed, $3.7 \%$ of the GDM diagnosis would be set by elevated 1-h values alone. This may be an overestimation as most would suggest that the discrepancy between fasting glucose values, on the one side, and 1- and 2-h glucose values, on the other side, would differ more than that between 1- and 2-h glucose values. However, altogether $17.8 \%$ was set by GDM and probably $<3.7 \%$ was set by 1 -h glucose values only. Accordingly, probably $<21 \%$ was set by 1-h glucose values. Thus, the modified IADPSG criteria without 1-h plasma glucose values presumably do not miss that many GDM cases compared with the original IADPSG criteria including 1 -h plasma glucose values.

\section{Laboratory methods}

Fasting plasma glucose levels were measured using venous blood samples drawn from an antecubital vein between 0800 and $1100 \mathrm{~h}$ after an overnight fast. Thereafter, a $75 \mathrm{~g}$ OGTT was performed and 2-h plasma samples were drawn. Blood samples were collected and processed in accordance with the local standardized procedures at the participating study centers.

DHEAS and sex hormone-binding globulins (SHBGs) were analyzed using the ELISA technique with the reagents and calibrators supplied by the manufacturer (DRG Instruments GmbH, Marburg, Lahn, Germany). We used the organic solvent extraction method (dichloromethane for testosterone and ethyl ether for androstenedione) prior to quantification to analyze serum testosterone and androstenedione concentrations. For quantification, we used the ELISA technique for testosterone (DRG Instruments $\mathrm{GmbH}$ ) and Coat-A-Count RIA Kits (Diagnostic Products Corporation, Los Angeles, CA, USA) for androstenedione. The intra- and interassay coefficients of variation were 6.6 and $4.0 \%$ for DHEAS, 5.3 and $2.8 \%$ for androstenedione, 11.9 and $9.1 \%$ for testosterone, and 12.0 and $2.0 \%$ for SHBGs respectively. Free testosterone index (FTI) was calculated as follows: (testosterone/ 
SHBGs) $\times 100$. Insulin levels were measured using the ELISA technique with the reagents and calibrators supplied by the manufacturer (DRG Instruments $\mathrm{GmbH})$. Insulin resistance was calculated using the homeostasis model assessment insulin resistance (HOMA-IR) formula (22).

\section{Study outcomes}

The primary outcome was the prevalence of GDM in PCOS women according to both the WHO and the modified IADPSG criteria of diagnosis. The secondary outcome was the risk factors for GDM according to the two sets of GDM criteria studied.

\section{Statistical analysis}

Baseline characteristics were calculated at inclusion. The prevalence of GDM during pregnancy was computed for different diagnostic criteria. Logistic regression analyses were performed to analyze the association between GDM and the considered risk factors. Risk factors significant at the $10 \%$ level in univariate analyses were included in the multivariate analyses. The characteristics of risk factors for normal glucose tolerance (NGT) women and GDM women were computed and equality in distribution was tested using the Wilcoxon's rank sum test.

\section{Results}

\section{Patient characteristics}

Two-hundred and seventy-three women with PCOS were included in the study. Mean age at inclusion was $29.4 \pm 4.4$ years. Mean weight and height were 80.9 $\pm 19.1 \mathrm{~kg}$ and $167.5 \pm 5.7 \mathrm{~cm}$ respectively. Mean BMI was $29.0 \pm 7.1 \mathrm{~kg} / \mathrm{m}^{2}$. The levels of DHEAS, SHBGs, androstenedione, testosterone, and FTI are given in Table 1. Mean insulin concentration was 15.9 $\pm 10.8 \mathrm{pmol} / \mathrm{l}$ and mean HOMA-IR was $3.29 \pm 7.1$.

\section{Prevalence of GDM}

The prevalence rates of GDM diagnosed after using the WHO and the modified IADPSG criteria were 9.2 and $15.0 \%, 18.7$ and $18.7 \%$, and 25.6 and $24.2 \%$ at gestational weeks 12,19 , and 32 respectively. The prevalence rates of GDM diagnosed using one set of criteria or both sets of criteria were $27.3,31.4$, and $33.1 \%$ at the different time points.

\section{Risk factors for GDM development according to the WHO criteria}

The risk factors for WHO-GDM at inclusion in the univariate analyses are given in Table 2. Only short
Table 1 Characteristics of 273 women with PCOS at inclusion in the first trimester. Values are given as mean \pm S.D. or number with percentage in parentheses as appropriate.

\begin{tabular}{lcc}
\hline Characteristics & $\boldsymbol{n}$ & Values \\
\hline Age (years) & 273 & $29.4 \pm 4.4$ \\
Weight $(\mathrm{kg})$ & 273 & $80.9 \pm 19.1$ \\
Height $(\mathrm{cm})$ & 273 & $167.5 \pm 5.7$ \\
BMl $\left(\mathrm{kg} / \mathrm{m}^{2}\right)$ & 273 & $29.0 \pm 7.1$ \\
Smoking $(n)$ & 272 & $23(8.5 \%)$ \\
Treatment group & 273 & \\
$\quad$ Metformin $(n)$ & & $135(49.5 \%)$ \\
Placebo $(n)$ & & $138(50.5 \%)$ \\
Menstruation & 273 & $36(13.2 \%)$ \\
Regular $(n)$ & & $195(71.4 \%)$ \\
Oligomenorrhea $(n)$ & & $42(15.4 \%)$ \\
Amenorrhea $(n)$ & & $4.87 \pm 2.14$ \\
DHEAS $(\mu \mathrm{mol} / \mathrm{l})$ & 266 & $213 \pm 94$ \\
SHBGs $(\mathrm{nmol} / \mathrm{l})$ & 266 & $12.1 \pm 7.6$ \\
Androstenedione $(\mathrm{nmol} / \mathrm{l})$ & 266 & $4.4 \pm 2.1$ \\
Testosterone $(\mathrm{nmol} / \mathrm{l})$ & 266 & $0.25 \pm 0.20$ \\
FTI & 266 & $15.9 \pm 10.8$ \\
Insulin (pmol/l) & 266 & $3.29 \pm 7.1$ \\
HOMA-IR & 266 & \\
\hline
\end{tabular}

stature and high insulin levels were significant risk factors for WHO-GDM at inclusion in the multivariate analyses.

The risk factors for WHO-GDM at week 19 in the univariate analyses are given in Table 3. Short stature and high insulin levels were significant risk factors for WHO-GDM at week 19 in the multivariate analyses.

At week 32, less weight gain in pregnancy was a significant risk factor for WHO-GDM in both the univariate and the multivariate analyses. Short stature was a significant risk factor for WHO-GDM in the multivariate analyses.

\section{Risk factors for GDM development according to the modified IADPSG criteria}

The risk factors for modified IADPSG-GDM at inclusion in the univariate analyses are given in Table 2. None of these variables were significant risk factors for modified IADPSG-GDM at inclusion in the multivariate analyses.

The risk factors for modified IADPSG-GDM at week 19 in the univariate analyses are given in Table 3. None of these variables were significant risk factors for modified IADPSG-GDM in the multivariate analyses.

The risk factors for modified IADPSG-GDM at week 32 in the univariate analyses are given in Table 4. Only reduced weight gain was a significant risk factor for modified IADPSG-GDM in the multivariate analyses.

\section{Maternal and offspring characteristics according to the GDM criteria}

Women with WHO-GDM lost less weight post-partum than those without WHO-GDM $(-5.7 \pm 1.1$ vs $-9.3 \pm$ $1.2 \mathrm{~kg} ; P=0.013)$. Children born to WHO-GDM women 
Table 2 Risk factors in the first trimester (at inclusion) for GDM throughout pregnancy according to different diagnostic criteria: univariate and multivariate analyses.

\begin{tabular}{|c|c|c|c|c|c|c|}
\hline & \multicolumn{3}{|c|}{$\mathbf{W H O}^{\mathrm{a}}$} & \multicolumn{3}{|c|}{ IADPSG $^{b}$} \\
\hline & $\beta$ & S.E.M. & $P$ value & $\beta$ & S.E.M. & $P$ value \\
\hline \multicolumn{7}{|l|}{ Univariate analyses } \\
\hline Age (years) & 0.064 & 0.033 & 0.050 & 0.057 & 0.034 & 0.093 \\
\hline Weight (kg) & 0.009 & 0.007 & 0.21 & 0.017 & 0.007 & 0.019 \\
\hline Height $(\mathrm{cm})$ & -0.063 & 0.026 & 0.017 & -0.018 & 0.026 & 0.48 \\
\hline $\operatorname{BMI}\left(\mathrm{kg} / \mathrm{m}^{2}\right)$ & 0.031 & 0.019 & 0.10 & 0.041 & 0.019 & 0.033 \\
\hline $\begin{array}{l}\text { Treatment group }(0=\text { metformin } \\
\text { and } 1=\text { placebo })\end{array}$ & 0.208 & 0.284 & 0.47 & 0.292 & 0.293 & 0.32 \\
\hline Parity $(n)$ & 0.318 & 0.193 & 0.099 & 0.29 & 0.206 & 0.16 \\
\hline Smoker $(1=$ yes and $0=$ no $)$ & 0.387 & 0.498 & 0.44 & 0.031 & 0.553 & 0.96 \\
\hline DHEAS $(\mu \mathrm{mol} / \mathrm{l})$ & 0.048 & 0.066 & 0.47 & 0.056 & 0.068 & 0.41 \\
\hline SHBG (nmol/l) & -0.003 & 0.002 & 0.096 & -0.004 & 0.002 & 0.032 \\
\hline Androstenedione $(\mathrm{nmol} / \mathrm{l})$ & -0.026 & 0.021 & 0.22 & -0.028 & 0.022 & 0.22 \\
\hline Testosterone (nmol/l) & 0.023 & 0.066 & 0.73 & -0.035 & 0.075 & 0.65 \\
\hline FTI & 0.850 & 0.975 & 0.38 & 1.453 & 1.002 & 0.15 \\
\hline Insulin (pmol/l) & 0.030 & 0.014 & 0.028 & 0.014 & 0.012 & 0.26 \\
\hline \multicolumn{7}{|l|}{ Multivariate analyses ${ }^{c}$} \\
\hline Age (years) & 0.054 & 0.038 & 0.15 & 0.052 & 0.035 & 0.14 \\
\hline Height $(\mathrm{cm})$ & -0.06 & 0.028 & 0.032 & & & \\
\hline Parity $(n)$ & 0.147 & 0.222 & 0.51 & & & \\
\hline SHBG (nmol/l) & -0.003 & 0.002 & 0.13 & -0.003 & 0.002 & 0.083 \\
\hline Insulin (pmol/l) & 0.027 & 0.013 & 0.044 & & & \\
\hline Weight $(\mathrm{kg})$ & & & & 0.015 & 0.016 & 0.37 \\
\hline $\mathrm{BMI}\left(\mathrm{kg} / \mathrm{m}^{2}\right)$ & & & & -0.008 & 0.044 & 0.85 \\
\hline
\end{tabular}

${ }^{\text {aT }}$ wo-hundred and six observations with non-missing risk factors.

${ }^{b}$ One-hundred and eighty-three observations with non-missing risk factors.

${ }^{c}$ Variables were included in the multivariate model if $P<0.1$ in the univariate analyses.

had less weight gain in the first year of their life than those born to women without WHO-GDM $(5.78 \pm 1.14$ vs $6.06 \pm 1.11 \mathrm{~kg} ; P=0.056)$. Women with modified IADPSG-GDM lost less weight post-partum than those without modified IADPSG-GDM $(-4.7 \pm 1.7$ vs $-9.9 \pm$
$1.2 \mathrm{~kg} ; P=0.026)$. Children born to women with modified IADPSG-GDM had less weight gain in the first year of their life than those born to women without modified IADPSG-GDM $(5.69 \pm 0.14$ vs 6.07 $\pm 0.11 \mathrm{~kg} ; P=0.025$; Table 5).

Table 3 Risk factors at week 19 for GDM throughout pregnancy according to different diagnostic criteria: univariate and multivariate analyses.

\begin{tabular}{|c|c|c|c|c|c|c|}
\hline & \multicolumn{3}{|c|}{$\mathrm{WHO}^{\mathrm{a}}$} & \multicolumn{3}{|c|}{ IADPSG $^{b}$} \\
\hline & $\beta$ & S.E.M. & $P$ value & $\beta$ & S.E.M. & $P$ value \\
\hline \multicolumn{7}{|l|}{ Univariate analyses } \\
\hline Weight $(\mathrm{kg})$ & 0.009 & 0.007 & 0.24 & 0.019 & 0.008 & 0.015 \\
\hline Weight increase since inclusion $(\mathrm{kg})$ & -0.043 & 0.053 & 0.42 & -0.067 & 0.056 & 0.23 \\
\hline BMI $\left(\mathrm{kg} / \mathrm{m}^{2}\right)$ & 0.04 & 0.021 & 0.058 & 0.056 & 0.022 & 0.01 \\
\hline DHEAS $(\mu \mathrm{mol} / \mathrm{l})$ & 0.09 & 0.078 & 0.26 & -0.012 & 0.085 & 0.89 \\
\hline SHBG $(\mathrm{nmol} / \mathrm{l})$ & -0.002 & 0.002 & 0.11 & -0.001 & 0.002 & 0.47 \\
\hline Androstenedione (nmol/l) & -0.034 & 0.029 & 0.23 & -0.039 & 0.03 & 0.19 \\
\hline Testosterone (nmol/l) & -0.122 & 0.08 & 0.13 & -0.121 & 0.082 & 0.14 \\
\hline FTI & -0.966 & 1.941 & 0.62 & -1.825 & 2.038 & 0.37 \\
\hline Insulin (pmol/l) & 0.031 & 0.013 & 0.019 & 0.032 & 0.014 & 0.025 \\
\hline \multicolumn{7}{|l|}{ Multivariate analyses $^{\mathrm{C}}$} \\
\hline Age (years) & 0.056 & 0.039 & 0.16 & 0.056 & 0.036 & 0.13 \\
\hline Height $(\mathrm{cm})$ & -0.07 & 0.029 & 0.017 & & & \\
\hline Parity $(n)$ & 0.079 & 0.226 & 0.73 & & & \\
\hline BMI $\left(\mathrm{kg} / \mathrm{m}^{2}\right)$ & -0.002 & 0.025 & 0.93 & 0.022 & 0.07 & 0.76 \\
\hline Insulin (pmol/l) & 0.039 & 0.016 & 0.014 & 0.027 & 0.016 & 0.094 \\
\hline Weight (kg) & & & & 0.003 & 0.024 & 0.90 \\
\hline
\end{tabular}

${ }^{\text {a }}$ Two-hundred and five observations with non-missing risk factors.

${ }^{b}$ One-hundred and seventy-eight observations with non-missing risk factors.

${ }^{c}$ Variables were included in the multivariate model if $P<0.1$ in the univariate analyses. 
Table 4 Risk factors at week 32 for GDM throughout pregnancy according to different diagnostic criteria: univariate and multivariate analysis.

\begin{tabular}{|c|c|c|c|c|c|c|}
\hline & \multicolumn{3}{|c|}{$\mathbf{W H O}^{\mathrm{a}}$} & \multicolumn{3}{|c|}{ IADPSG $^{b}$} \\
\hline & $\beta$ & S.E.M. & $P$ value & $\beta$ & S.E.M. & $P$ value \\
\hline \multicolumn{7}{|l|}{ Univariate analyses } \\
\hline Weight (kg) & 0.007 & 0.008 & 0.392 & 0.019 & 0.008 & 0.02 \\
\hline $\begin{array}{l}\text { Weight increase from inclusion to } \\
\text { week } 36(\mathrm{~kg})\end{array}$ & -0.110 & 0.036 & 0.002 & -0.104 & 0.037 & 0.005 \\
\hline $\operatorname{BMl}\left(\mathrm{kg} / \mathrm{m}^{2}\right)$ & 0.038 & 0.023 & 0.092 & 0.058 & 0.023 & 0.011 \\
\hline DHEAS $(\mu \mathrm{mol} / \mathrm{l})$ & -0.067 & 0.099 & 0.5 & -0.187 & 0.111 & 0.093 \\
\hline SHBG (nmol/l) & 0.00 & 0.001 & 0.75 & 0.00 & 0.001 & 0.81 \\
\hline Androstenedione (nmol/l) & -0.044 & 0.021 & 0.04 & -0.046 & 0.022 & 0.038 \\
\hline Testosterone (nmol/l) & -0.087 & 0.057 & 0.13 & -0.058 & 0.053 & 0.28 \\
\hline FTI & -3.187 & 1.951 & 0.10 & -1.769 & 1.738 & 0.31 \\
\hline Insulin (pmol/l) & 0.01 & 0.012 & 0.44 & 0.017 & 0.013 & 0.17 \\
\hline \multicolumn{7}{|l|}{ Multivariate analyses ${ }^{c}$} \\
\hline Age (years) & 0.024 & 0.042 & 0.57 & 0.017 & 0.04 & 0.68 \\
\hline Height $(\mathrm{cm})$ & -0.06 & 0.029 & 0.039 & & & \\
\hline Parity $(n)$ & -0.006 & 0.241 & 0.98 & & & \\
\hline Weight increase since week 12 (kg) & -0.112 & 0.039 & 0.004 & -0.111 & 0.047 & 0.018 \\
\hline BMI $\left(\mathrm{kg} / \mathrm{m}^{2}\right)$ & 0.015 & 0.025 & 0.56 & 0.072 & 0.076 & 0.34 \\
\hline Androstenedione (nmol/l) & -0.038 & 0.022 & 0.089 & -0.03 & 0.023 & 0.19 \\
\hline Weight $(\mathrm{kg})$ & & & & -0.005 & 0.026 & 0.86 \\
\hline DHEAS $(\mu \mathrm{mol} / \mathrm{l})$ & & & & -0.121 & 0.124 & 0.33 \\
\hline
\end{tabular}

${ }^{a}$ One-hundred and ninety-four observations with non-missing risk factors.

bone-hundred and seventy observations with non-missing risk factors.

${ }^{c}$ Variables were included in the multivariate model if $P<0.1$ in the univariate analyses.

\section{Discussion}

In the present post hoc analysis of a randomized, multicenter study, we found that the WHO and the modified IADPSG criteria for GDM diagnosis identify the same number of women with GDM. Early in pregnancy, however, more women meet the GDM criteria according to the modified IADPSG criteria than according to the WHO criteria. Women diagnosed according to the two sets of criteria differ in patient characteristics and in risk factors of GDM development. Less than one-third of the women with GDM according to either of the criteria sets fulfilled both diagnostic modes. GDM diagnosis correlated with less maternal weight loss the first year post-partum.

A general increase in GDM incidence when using the IADPSG criteria instead of the WHO criteria is well documented $(23,24)$. To our knowledge, the prevalence of GDM according to the IADPSG criteria in PCOS women has not been reported previously. Contrary to most other studies that have reported a higher prevalence rate of GDM when applying the IADPSG criteria than when applying the WHO criteria, we found similar prevalence rates of GDM irrespective of the mode of diagnosis in women with PCOS. Of course, an explanation for this may be that we used the modified IADPSG criteria without 1-h glucose values and thus reported lower GDM incidence than what the truth is. However, as has been outlined previously, adding 1-h plasma glucose values probably increases GDM incidence by $<21 \%$. The confirmation of our findings in future studies would result in the possibility of the pathogenesis for GDM in women with PCOS being different from that for women without PCOS.

Table 5 Offspring and maternal characteristics for different diagnostic criteria.

\begin{tabular}{|c|c|c|c|c|c|c|}
\hline & \multicolumn{3}{|c|}{ WHO } & \multicolumn{3}{|c|}{ IADPSG } \\
\hline & \multirow{2}{*}{$\begin{array}{l}\text { NGT }(n=128) \\
\text { Mean } \pm \text { s.E.M. }\end{array}$} & \multicolumn{2}{|c|}{ GDM $(n=59)$} & \multirow{2}{*}{$\begin{array}{l}\text { NGT }(n=122) \\
\text { Mean } \pm \text { s.E.M. }\end{array}$} & \multicolumn{2}{|c|}{ GDM $(n=52)$} \\
\hline & & Mean \pm S.E.M. & $P$ value & & Mean \pm S.E.M. & $P$ value \\
\hline Birth weight (g) & $3547 \pm 48$ & $3522 \pm 78$ & 0.71 & $3516 \pm 50$ & $3567 \pm 78$ & 0.59 \\
\hline Offspring weight at 1 year $(\mathrm{kg})$ & $9.98 \pm 0.11$ & $9.69 \pm 0.15$ & 0.091 & $9.96 \pm 0.12$ & $9.65 \pm 0.15$ & 0.17 \\
\hline Offspring weight change in the first year $(\mathrm{kg})$ & $6.06 \pm 0.11$ & $5.78 \pm 0.14$ & 0.056 & $6.07 \pm 0.11$ & $5.69 \pm 0.14$ & 0.025 \\
\hline Maternal weight at week $36(\mathrm{~kg})$ & $91.1 \pm 1.9$ & $88.9 \pm 2.40$ & 0.9 & $90.3 \pm 1.9$ & $92.3 \pm 3.0$ & 0.44 \\
\hline Maternal weight 1 year post-partum (kg) & $81.1 \pm 2.0$ & $82.9 \pm 2.3$ & 0.19 & $79.7 \pm 1.9$ & $87.1 \pm 3.2$ & 0.033 \\
\hline Maternal weight change post-partum (kg) & $-9.3 \pm 1.2$ & $-5.7 \pm 1.1$ & 0.013 & $-9.9 \pm 1.2$ & $-4.7 \pm 1.7$ & 0.026 \\
\hline Maternal BMI at week $36\left(\mathrm{~kg} / \mathrm{m}^{2}\right)$ & $31.8 \pm 0.7$ & $31.7 \pm 0.9$ & 0.66 & $31.7 \pm 0.7$ & $32.6 \pm 1.1$ & 0.31 \\
\hline Maternal BMI 1 year post-partum $\left(\mathrm{kg} / \mathrm{m}^{2}\right)$ & $28.3 \pm 0.7$ & $29.3 \pm 0.8$ & 0.11 & $27.9 \pm 0.7$ & $30.6 \pm 1.1$ & 0.025 \\
\hline Maternal BMI change $\left(\mathrm{kg} / \mathrm{m}^{2}\right)$ & $-2.9 \pm 0.4$ & $-1.7 \pm 0.4$ & 0.017 & $-3.2 \pm 0.42$ & $-1.3 \pm 0.57$ & 0.015 \\
\hline
\end{tabular}


Risk factors for GDM throughout pregnancy vary by the diagnostic criteria used. At inclusion and at week 19, short stature and high insulin levels were the risk factors for WHO-GDM throughout pregnancy, but not for modified IADPSG-GDM throughout pregnancy. Short stature has lately emerged as a risk factor for GDM in women without PCOS (25). Interestingly, less weight gain in pregnancy predicted GDM in late pregnancy according to both the WHO and the modified IADPSG criteria. This observation contradicts common wisdom and the vast majority of scientific reports in which increased weight gain has been reported to be associated with $\operatorname{GDM}(26,27,28,29,30)$. One report, however, supports our finding (31). A possible explanation may be that GDM occurs more frequently in obese women, and obese women gain less weight during pregnancy than those with normal prepregnancy weight. Our data, however, show no difference in baseline BMI between women who developed GDM and those who did not. Possibly it is PCOS per se and not obesity that is associated with GDM. Han et al. (32), however, found that GDM morbidity was significantly higher in obese PCOS women than in nonobese PCOS women, suggesting that GDM is associated with obesity and not with PCOS per se. A high prevalence of elevated $\mathrm{HbA1c}$ levels in nonobese women with PCOS and an increased risk of elevated $\mathrm{HbAlc}$ levels in PCOS in a recent case-control study, however, support our hypothesis (33). The authors of the latter study suggest that $\mathrm{HbA} 1 \mathrm{c}$ as a diagnostic tool in diabetes screening may be of help in young nonobese PCOS women. A recent Danish retrospective observational study of PCOS women, on the other hand, has found HbAlc to be a poor marker in diagnosing type 2 diabetes, but found $\mathrm{HbA1c}$ to be associated with BMI, waist and lipid profiles, thus suggesting its role as a cardiovascular risk marker in women with PCOS (34).

Post-partum, GDM diagnosis correlates with less maternal weight loss irrespective of the mode of GDM diagnosis. The association between GDM and later type 2 diabetes mellitus is well documented (35). Our data indicate that this association may partly be explained by the lower weight loss post-partum and not so much by the diagnosis of GDM itself. In a pilot randomized trial, Ferrara et al. (36) have recently reported that GDM women receiving prenatal/post-partum intervention to modify diet and physical activity show a higher probability of reaching post-partum weight goal (defined as prepregnancy weight if BMI $<25 \mathrm{~kg} / \mathrm{m}^{2}$ and $-5 \%$ of prepregnancy weight if BMI $>25 \mathrm{~kg} / \mathrm{m}^{2}$ ) 12 months post-partum. The associations among maternal weight changes, HbA1c levels in PCOS women, GDM, type 2 diabetes, and later cardiovascular disease should be explored further.

Less than one-third of women with GDM met both the WHO and the modified IADPSG criteria. The discrepancy between WHO-GDM prevalence and modified IADPSG-GDM prevalence was highest early in pregnancy. Given the well-documented adverse effects of GDM, early detection may improve maternal and fetal outcomes $(37,38,39)$. The high discrepancy between WHO-GDM prevalence and modified IADPSG-GDM prevalence in early pregnancy in women with PCOS is noteworthy and should be explored further before changing routines.

A weakness of the study is the high and partly divergent intra- and interassay coefficients, especially concerning testosterone and SHBG levels. Furthermore, women diagnosed with GDM according to the WHO criteria in the original RCT got more thorough diet advice than did the entire study population, potentially influencing WHO-GDM outcomes throughout pregnancy and the extent of diagnostic overlap between the WHO and the modified IADPSG criteria in this post hoc analysis. The strengths of the study are the homogenous population of Caucasian women with well-documented PCOS and a structured follow-up with three OGTT measurements in pregnancy. The small number of dropouts, the high prevalence of GDM, and the frequent laboratory hormone analyses are also advantages. To our knowledge, no other report of comparable size and quality comparing GDM incidence and risk factors according to different diagnostic GDM criteria in women with PCOS has been published.

\section{Conclusion}

The WHO and the modified IADPSG criteria for GDM diagnosis identify the same number of women with PCOS throughout pregnancy. However, less than onethird of PCOS women with GDM fulfill the two sets of diagnostic criteria. Risk factors for GDM differ according to the diagnostic criteria used, but less weight gain in pregnancy seems to be a risk factor independent of the mode of diagnosis. Less maternal weight loss the first year post-partum in PCOS women with GDM can partly explain the well-known association between GDM and later type 2 diabetes mellitus.

\section{Declaration of interest}

The authors declare that there is no conflict of interest that could be perceived as prejudicing the impartiality of the research reported.

\section{Funding}

Metformin and placebo tablets were delivered free of charge by Weifa A/S (Oslo, Norway). Weifa had no involvement in the study. We received grants from the Liaison Committee between the Central Norway Regional Health Authority and the Norwegian University of Science and Technology. No other specific grants from any funding agency in the public, commercial, or not-for-profit sector were received.

\section{Author contribution statement}

S M Carlsen and E Vanky made substantial contributions to the conception and design of the randomized multicenter study and 
revised the manuscript critically before submission. S M Carlsen created study aims. Ø Salvesen computed the statistical analyses with substantial contribution from S M Carlsen. R Helseth wrote drafts of the article and made substantial contributions to the final version to be published.

\section{Acknowledgements}

We thank the patients for their loyal participation in the study.

\section{References}

1 Buckley BS, Harreiter J, Damm P, Corcoy R, Chico A, Simmons D, Vellinga A, Dunne F \& Group DCI. Gestational diabetes mellitus in Europe: prevalence, current screening practice and barriers to screening. A review. Diabetic Medicine $201229844-854$. (doi:10.1111/j.1464-5491.2011.03541.x)

2 Konig M \& Shuldiner AR. The genetic interface between gestational diabetes and type 2 diabetes. Journal of Maternal-Fetal $\mathcal{E}$ Neonatal Medicine 201225 36-40. (doi:10.3109/14767058. 2012.626926)

3 Bottalico JN. Recurrent gestational diabetes: risk factors, diagnosis, management, and implications. Seminars in Perinatology 200731 176-184. (doi:10.1053/j.semperi.2007.03.006)

4 Lopez-Tinoco C, Roca M, Fernandez-Deudero A, Garcia-Valero A, Bugatto F, Aguilar-Diosdado M \& Bartha JL. Cytokine profile, metabolic syndrome and cardiovascular disease risk in women with late-onset gestational diabetes mellitus. Cytokine $2012 \mathbf{5 8}$ 14-19. (doi:10.1016/j.cyto.2011.12.004)

5 Sullivan SD, Umans JG \& Ratner R. Gestational diabetes: implications for cardiovascular health. Current Diabetes Reports 201212 43-52. (doi:10.1007/s11892-011-0238-3)

6 Tam WH, Ma RC, Yang X, Ko GT, Lao TT, Chan MH, Lam CW, Cockram CS \& Chan JC. Cardiometabolic risk in Chinese women with prior gestational diabetes: a 15-year follow-up study. Gynecologic and Obstetric Investigation 201273 168-176. (doi:10.1159/000329339)

7 Hapo Study Cooperative Research Group , Metzger BE, Lowe LP, Dyer AR, Trimble ER, Chaovarindr U, Coustan DR, Hadden DR, McCance DR, Hod M et al. Hyperglycemia and adverse pregnancy outcomes. New England Journal of Medicine 2008358 1991-2002. (doi:10.1056/NEJMoa0707943)

8 International Association of Diabetes Pregnancy Study Groups Consensus Panel, Metzger BE, Gabbe SG, Persson B, Buchanan TA, Catalano PA, Damm P, Dyer AR, Leiva A, Hod M et al. International association of diabetes and pregnancy study groups recommendations on the diagnosis and classification of hyperglycemia in pregnancy. Diabetes Care 201033 676-682. (doi:10.2337/dc09-1848)

9 Jenum AK, Morkrid K, Sletner L, Vangen S, Torper JL, Nakstad B, Voldner N, Rognerud-Jensen OH, Berntsen S, Mosdol A et al. Impact of ethnicity on gestational diabetes identified with the WHO and the modified International Association of Diabetes and Pregnancy Study Groups criteria: a population-based cohort study. European Journal of Endocrinology 2012166 317-324. (doi:10.1530/EJE-11-0866)

10 Asuncion M, Calvo RM, San Millan JL, Sancho J, Avila S \& Escobar-Morreale HF. A prospective study of the prevalence of the polycystic ovary syndrome in unselected Caucasian women from Spain. Journal of Clinical Endocrinology and Metabolism 200085 2434-2438. (doi:10.1210/jc.85.7.2434)

11 Eilertsen TB, Vanky E \& Carlsen SM. Increased prevalence of diabetes and polycystic ovary syndrome in women with a history of preterm birth: a case-control study. BJOG: an International Journal of Obstetrics and Gynaecology $2012119266-275$. (doi:10.1111/j.1471-0528.2011.03206.x)

12 Rotterdam ESHRE/ASRM-Sponsored PCOS Consensus Workshop Group. Revised 2003 consensus on diagnostic criteria and long-term health risks related to polycystic ovary syndrome (PCOS). Human Reproduction 200419 41-47. (doi:10.1093/ humrep/deh098)

13 Altieri P, Gambineri A, Prontera O, Cionci G, Franchina M \& Pasquali R. Maternal polycystic ovary syndrome may be associated with adverse pregnancy outcomes. European Journal of Obstetrics, Gynecology, and Reproductive Biology 2010149 31-36. (doi:10.1016/j.ejogrb.2009.11.010)

14 Ghazeeri GS, Nassar AH, Younes Z \& Awwad JT. Pregnancy outcomes and the effect of metformin treatment in women with polycystic ovary syndrome: an overview. Acta Obstetricia et Gynecologica Scandinavica 201291 658-678. (doi:10.1111/ j.1600-0412.2012.01385.x)

15 Iavazzo C \& Vitoratos N. Polycystic ovarian syndrome and pregnancy outcome. Archives of Gynecology and Obstetrics 2010 282 235-239. (doi:10.1007/s00404-010-1495-0)

16 Lambrinoudaki I. Cardiovascular risk in postmenopausal women with the polycystic ovary syndrome. Maturitas 201168 13-16. (doi:10.1016/j.maturitas.2010.09.005)

17 Reyes-Munoz E, Castellanos-Barroso G, Ramirez-Eugenio BY, Ortega-Gonzalez C, Parra A, Castillo-Mora A \& De la Jara-Diaz JF. The risk of gestational diabetes mellitus among Mexican women with a history of infertility and polycystic ovary syndrome. Fertility and Sterility 201297 1467-1471. (doi:10.1016/j.fertnstert. 2012.03.023)

18 Alshammari A, Hanley A, Ni A, Tomlinson G \& Feig DS. Does the presence of polycystic ovary syndrome increase the risk of obstetrical complications in women with gestational diabetes? Journal of Maternal-Fetal \& Neonatal Medicine 201023 545-549. (doi:10.3109/14767050903214566)

19 Boutzios G, Livadas S, Piperi C, Vitoratos N, Adamopoulos C, Hassiakos D, Iavazzo C \& Diamanti-Kandarakis E. Polycystic ovary syndrome offspring display increased oxidative stress markers comparable to gestational diabetes offspring. Fertility and Sterility 201223 943-950.

20 Vanky E, Stridsklev S, Heimstad R, Romundstad P, Skogoy K, Kleggetveit O, Hjelle S, von Brandis P, Eikeland T, Flo K et al. Metformin versus placebo from first trimester to delivery in polycystic ovary syndrome: a randomized, controlled multicenter study. Journal of Clinical Endocrinology and Metabolism 201095 E448-E455. (doi:10.1210/jc.2010-0853)

21 Vanky E, Stridsklev S, Skogoy K, Kleggetveit O, Hjelle S, Brandis PV, Eikeland T, Flo K, Berg KF, Bunford G et al. PCOS - what matters in early pregnancy? - data from a cross-sectional, multicenter study. Acta Obstetricia et Gynecologica Scandinavica 201190 398-404. (doi:10.1111/j.1600-0412.2010.01064.x)

22 Matthews DR, Hosker JP, Rudenski AS, Naylor BA, Treacher DF \& Turner RC. Homeostasis model assessment: insulin resistance and $\beta$-cell function from fasting plasma glucose and insulin concentrations in man. Diabetologia 198528 412-419. (doi:10.1007/ BF00280883)

23 Langer O, Umans JG \& Miodovnik M. The proposed GDM diagnostic criteria: a difference, to be a difference, must make a difference. Journal of Maternal-Fetal \& Neonatal Medicine 201226 111-115.

24 Long $\mathrm{H} \&$ Cundy T. Establishing consensus in the diagnosis of gestational diabetes following HAPO: where do we stand? Current Diabetes Reports 201213 43-50. (doi:10.1007/s11892-0120330-3)

25 Anastasiou E, Alevizaki M, Grigorakis SJ, Philippou G, Kyprianou M \& Souvatzoglou A. Decreased stature in gestational diabetes mellitus. Diabetologia 199841 997-1001. (doi:10.1007/ s001250051022)

26 Carreno CA, Clifton RG, Hauth JC, Myatt L, Roberts JM, Spong CY, Varner MW, Thorp JM Jr, Mercer BM, Peaceman AM et al. Excessive early gestational weight gain and risk of gestational diabetes mellitus in nulliparous women. Obstetrics and Gynecology 2012119 1227-1233. (doi:10.1097/AOG. Ob013e318256cf1a) 
27 Gibson KS, Waters TP \& Catalano PM. Maternal weight gain in women who develop gestational diabetes mellitus. Obstetrics and Gynecology 2012119 560-565. (doi:10.1097/AOG.0b013e31 $824758 \mathrm{e} 0)$

28 Hedderson MM, Gunderson EP \& Ferrara A. Gestational weight gain and risk of gestational diabetes mellitus. Obstetrics and Gynecology 2010115 597-604. (doi:10.1097/AOG.0b013e 3181 cfce 4 f)

29 Morisset AS, Dube MC, Drolet R, Robitaille J, Weisnagel SJ \& Tchernof A. Sex hormone-binding globulin levels and obesity in women with gestational diabetes: relationship with infant birthweight. Gynecological Endocrinology 201127 905-909. (doi:10.3109/09513590.2011.569602)

30 Morisset AS, St-Yves A, Veillette J, Weisnagel SJ, Tchernof A \& Robitaille J. Prevention of gestational diabetes mellitus: a review of studies on weight management. Diabetes/Metabolism Research and Reviews 201026 17-25. (doi:10.1002/dmrr.1053)

31 Stewart ZA, Wallace EM \& Allan CA. Patterns of weight gain in pregnant women with and without gestational diabetes mellitus: an observational study. Australian $\mathcal{E}$ New Zealand Journal of Obstetrics E Gynaecology 201252 433-439. (doi:10.1111/ajo.12001)

32 Han RK, Ungar WJ \& Macarthur C. Cost-effectiveness analysis of a proposed public health legislative/educational strategy to reduce tap water scald injuries in children. Injury Prevention 2007 13 248-253. (doi:10.1136/ip.2006.014480)

33 Kim JJ, Choi YM, Cho YM, Jung HS, Chae SJ, Hwang KR, Hwang SS, Ku SY, Kim SH, Kim JG et al. Prevalence of elevated glycated hemoglobin in women with polycystic ovary syndrome. Human Reproduction 201227 1439-1444. (doi:10.1093/hum$\mathrm{rep} / \mathrm{des} 039$ )

34 Velling Magnussen L, Mumm H, Andersen M \& Glintborg D. Hemoglobin A1c as a tool for the diagnosis of type 2 diabetes in 208 premenopausal women with polycystic ovary syndrome. Fertility and Sterility 201196 1275-1280. (doi:10.1016/ j.fertnstert.2011.08.035)

35 Tobias DK, Hu FB, Chavarro J, Rosner B, Mozaffarian D \& Zhang C. Healthful dietary patterns and type 2 diabetes mellitus risk among women with a history of gestational diabetes mellitus. Archives of Internal Medicine $2012 \mathbf{1 7 2}$ 1566-1572. (doi:10.1001/archinternmed.2012.3747)

36 Ferrara A, Hedderson MM, Albright CL, Ehrlich SF, Quesenberry CP Jr, Peng T, Feng J, Ching J \& Crites Y. A pregnancy and postpartum lifestyle intervention in women with gestational diabetes mellitus reduces diabetes risk factors: a feasibility randomized control trial. Diabetes Care 201134 1519-1525. (doi:10.2337/dc10-2221)

37 Bonomo M, Corica D, Mion E, Goncalves D, Motta G, Merati R, Ragusa A \& Morabito A. Evaluating the therapeutic approach in pregnancies complicated by borderline glucose intolerance: a randomized clinical trial. Diabetic Medicine 200522 1536-1541. (doi:10.1111/j.1464-5491.2005.01690.x)

38 Crowther CA, Hiller JE, Moss JR, McPhee AJ, Jeffries WS, Robinson JS \& Australian Carbohydrate Intolerance Study in Pregnant Women Trial G . Effect of treatment of gestational diabetes mellitus on pregnancy outcomes. New England Journal of Medicine 2005352 2477-2486. (doi:10.1056/NEJMoa042973)

39 Langer O, Yogev Y, Most O \& Xenakis EM. Gestational diabetes: the consequences of not treating. American Journal of Obstetrics and Gynecology 2005192 989-997. (doi:10.1016/j.ajog.2004.11.039)

Received 22 December 2012

Revised version received 12 April 2013

Accepted 1 May 2013 